\section{Self- and Cross-pollination Affect Stigmatic Pollen Saturation in Blueberry}

\author{
E. James Parrie and Gregory A. Lang ${ }^{1}$ \\ Department of Horticulture, Louisiana Agricultural Experiment Station, \\ Louisiana State University Agricultural Center, Baton Rouge, LA 70803
}

Additional index words. southern highbush blueberry, northern highbush blueberry, halfhigh blueberry, Vaccinium corymbosum, V. ashei, V. darrowi, V. angustifolium, incompatibility, stigmatic exudate

\begin{abstract}
Pollen deposition on the stigmatic surface of blueberry pistils was studied with regard to maximum pollen load and stigmatic fluid production (stigma receptivity). Three hybrid southern highbush cultivars (Vaccinium corymbosum L. with $V$. darrowi Camp, V. ashei Reade, and/or V. angustfolium Aiton), two northern highbush cultivars ( $V$. corymbosum), and one hybrid half-high cultivar ( $V$. corymbosum with $V$. angustifolium) were self- and cross-pollinated with counted pollen tetrads until saturation of the stigmatic surface occurred. Stigmatic saturation generally required 200 to 300 tetrads and was characterized by the cessation of stigmatic fluid production and the inability to absorb further tetrads. The loss of stigmatic receptivity was irreversible. Cross-pollination resulted in cessation of stigmatic fluid production at lower levels of tetrad deposition than did self-pollination, suggesting a potential pollen-stigma recognition phenomenon. Northern highbush, half-high, and southern highbush cultivars required $7 \%$ to $10 \%, 12 \%$ to $17 \%$, and $14 \%$ to $21 \%$, respectively, more self-pollen to develop the stigmatic saturation condition. The potential relation of the pollenstigma phenomenon to self-incompatibility mechanisms is discussed.
\end{abstract}

The recent development of southern highbush blueberry cultivars, which are complex hybrids of Vaccinium corymbosum with $V$. darrowi, $V$. ashei, and $V$. angustifolium, provides blueberry growers of the coastal plains of the Gulf of Mexico with a new

Received for publication 12 Nov. 1991. Accepted for publication 17 June 1992. Approved for publication by the Director of the Louisiana Agricultural Experiment Station as manuscript no. 91-28. 5325. We thank P.T. Evans. N.S. Lane. and E.N. O'Rourke for their critical reviews of the manuscript. The cost of publishing this paper was defrayed in part by the payment of page charges. Under postal regulations, this paper therefore must be hereby marked advertisement solely to indicate this fact.

${ }^{\mathrm{I}}$ To whom reprint requests should be addressed. market based on early ripening fruit (Lang and Danka, 1992, Lyrene and Sherman, 1984). To study factors that influence fruit development and ripening in multiseeded fruits such as the blueberry, pollination events that may affect seed count and development also must be considered. Little is currently known about the biology of pollen deposition on the blueberry flower stigma, subsequent effects on fruit development, or relationships to pollinator activity.

In some plants, as the amount of pollen deposited on the stigma increases, pollen germination has been shown to increase (Stephenson and Bertin, 1983). Increasing the pollen density on the stigma also has been shown to alleviate or reduce self-incompatibility systems in raspberry (Rubus idaeus
L.) (Jennings and Topham, 1971) and various other angiosperms (Brewbaker and Majumder, 1961).

Pollen hydration on the stigmatic surface is not yet well understood and has only recently been considered a potential point of pollen-stigma recognition events (Dumas and Gaude, 1981). Pollen hydration is an active phenomenon that is probably initiated by interaction between the outer layer of the exine and the stigmatic exudate (Dumas et al., 1986) and involves increases in protein synthesis (Sarker et al., 1988) and ATPase activity that are sensitive to stigmatic exudate $\mathrm{pH}$ (Gudin and Arene, 1991).

Southern highbush blueberry genomes are a complex mixture of genes from generally self-compatible $V$. corymbosum and other species that are largely self-incompatible, and little is known about the pollen compatibilities or gynoecious interactions of southern highbush cultivars (Lang and Danka, 1991a, 1991b). Self-pollen from blueberry germplasm of various ploidy levels has been reported to germinate readily after deposition (El-Agamy et al., 1982). The objective of this experiment was to develop quantitative data for maximum pollen depositions on blueberry stigmas for self- and cross-compatibility studies.

Plant materials. Dormant J-year-old potted 'Gulfcoast', 'Georgiagem', and 'O'Neal' southern highbush blueberry plants were moved into 7C storage rooms in January to fully satisfy their chilling requirements. Floral budbreak was forced 4 weeks later at $25 \mathrm{C}$ in the laboratory. In May, 3-year-old potted 'Meader' and 'Bluechip' northern highbush and 'Northland' half-high blueberry plants were obtained from a Michigan nursery at the budbreak stage and allowed to flower under ambient conditions ( 22 to $24 \mathrm{C}$ days) in a shadehouse (35\% of photosynthetically active radiation). All plants were fertilized with $15 \mathrm{~g} 19 \mathrm{~N}-1.3 \mathrm{P}-8.2 \mathrm{~K}$ slow-release fertilizer (Osmocote).

Treatments. All treatments were applied under ambient laboratory conditions $(\approx 25 \mathrm{C}$ and $60 \%$ to $65 \%$ relative humidity). Fresh pollen was collected randomly from flowers of the same age ( $24 \mathrm{~h}$ after corolla opening) 

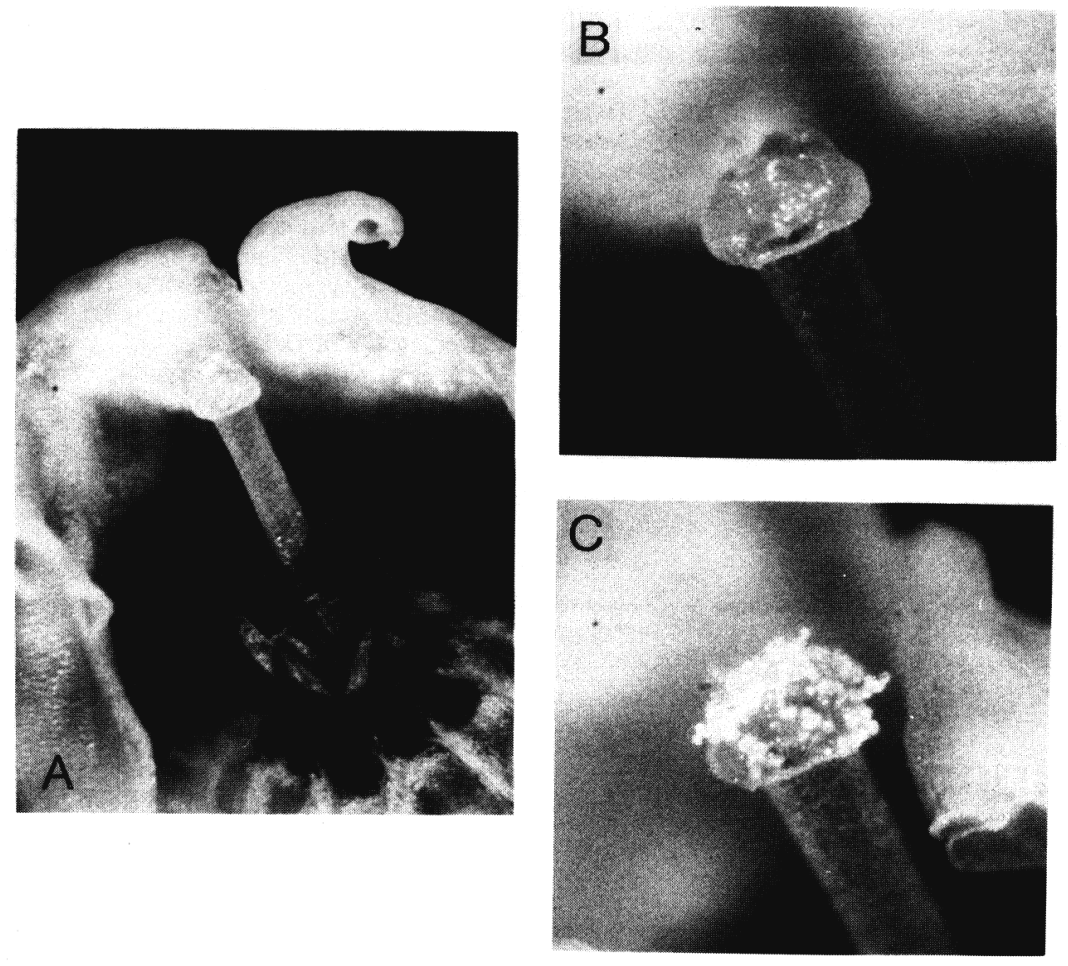

Fig. 1. Pollen deposition and absorption to the stigmatic fluid/papillae matrix of the blueberry pistil. (A) A fully receptive, unpollinated blueberry stigma $(\times 20)$; (B) during pollen deposition, absorption of pollen tetrads into the stigmatic fluid/papillae near the Point of stigmatic saturation $(\times 25) ;(\mathbf{C})$ excess pollen tetrads adhering to the stigmatic surface after the point of saturation $(\times 25)$.

at various shoot locations within and among the plants of each cultivar and pooled for use as a treatment. Pollen collection and application was replicated over several days, using new plants on which anthesis was $\approx 50 \%$ each day. Pollen treatments were applied as selfpollinations for each cultivar. Additionally, each southern highbush cultivar was crosspollinated with the other two southern highbush cultivars, and each northern highbush or half-high cultivar was cross-pollinated individually with its corresponding other two cultivars.

Pollen was applied in a completely random design with respect to pollen source and treated inflorescences, each of which contained five flowers. A single plant of each cultivar received all three treatments twice, yielding two subsamples per plant. All treatments were applied to complete a replication before the next replication was begun, minimizing any potential confounding effects of application time. A total of 27 single-plant replications per southern highbush cultivar was completed over 5 days, and eight replications per northern highbush or half-high cultivar were completed over 3 days.

Pollen application. All pollen applications were made on stigmas of flowers that had opened $24 \mathrm{~h}$ earlier. To quantify the number of pollen tetrads applied to the stigmatic surface of the pistil, tetrads were placed onto a thumbnail painted black (for contrast) and counted under a dissecting microscope $(\times 25)$. A magnifying lens with attached headband (Model 117 Magni-Focuser, Edroy Products, Nyack, N.Y.) was worn for magnifi- cation $(\times 5.25)$ during pollen transfer to the stigma. After each transfer, the thumbnail was examined under the dissecting microscope to verify the number of tetrads that had been transferred. This procedure was continued on each flower until stigmatic saturation occurred. Stigmatic saturation is defined as the condition in which the stigma is incapable of absorbing and hydrating an additional 10 to 15 pollen tetrads interspersed across the stimatic surface. The surface appearance of a saturated stigma was gel-like compared with that of nonsaturated stigmas, which maintained a liquid appearance. The time required to deposit saturating amounts of pollen on each stigma averaged $\approx 10 \mathrm{~min}$, although individual durations for each pollination treatment were not recorded.

The accuracy of the pollen application procedure was examined in a preliminary trial of 20 transfers of 100 pollen tetrads each to a glass rod. The number of tetrads both remaining on the thumbnail and successfully transferred to the rod were determined under the dissecting microscope, resulting in an overall SE Of 0.3 per transfer.

All data were analyzed by analysis of variance, and mean separations were calculated by Duncan's multiple range test.

Stigmatic saturation. During the course of pollen deposition to the stigmatic surface, the ability of the stigma to absorb and hydrate pollen decreased. Stigmas on fully receptive, unpollinated pistils had a uniformly rounded appearance and a very fluid surface (Fig. 1A). Pollen tetrads applied to the stigma were absorbed into this fluid/papillae matrix, which developed a nonuniform, irregular surface as more pollen was applied (Fig. 1B). Once stigmatic saturation occurred, pollen tetrads began adhering to the stigmatic surface, rather than being absorbed into the fluid/ papillae matrix (Fig. 1C). At this point, stigmatic receptivity was irreversibly lost as stigmatic fluid production apparently ceased, followed by desiccation of the stigma and browning of the style within $24 \mathrm{~h}$ (unpublished data).

The anatomical and physiological changes described above for blueberry stigmatic saturation may be analogous to those described by Wetzstein and Sparks (1989) for pecan [Carya illinoinensis (Wangenh.) K. Koch] pollination. Scanning electron microscopy of pecan pollen on a fully receptive pecan stigma showed that as pollen grains were hydrated, the adjacent stigmatic papillae became desiccated and collapsed. These collapsed papillae began to deteriorate shortly thereafter and could not be rehydrated.

In the southern highbush cultivars, the number of pollen tetrads required for stigmatic saturation ranged from 200 in crosspollinated 'O'Neal' to nearly 300 in self-pollinated 'Gulfcoast' and 'Georgiagem' (Table 1). Of coincidental interest is the similarity in number of tetrads for stigmatic saturation in the latter two cultivars, which share the same paternal parent ('US-75') and have a common pollen donor ('Earliblue') in their maternal heritage. For within-cultivar treatments, self-pollinations consistently required more pollen tetrads for stigmatic saturation than did either cross-pollination combination, ranging from $14 \%$ to $18 \%$ more selfpollen-in 'Georgiagem' to $16 \%$ to $21 \%$ more in 'O'Neal' and 'Gulfcoast'. Cross-pollen sources did not differ significantly within cultivar treatments.

Due to the striking and significant differences in stigmatic pollen saturation between self- and cross-pollinations in the southern highbush cultivars, the experiment was repeated on two northern highbush cultivars and a northern half-high blueberry cultivar. The number of pollen tetrads required for stigmatic saturation in these cultivars ranged from 185 in cross-pollinated 'Northland' to 256 in self-pollinated 'Meader' (Table 2). Once again, more tetrads were required for stigmatic saturation with self-pollination than for cross-pollination; for each experiment, the amount of outcross pollen required for stigmatic saturation did not differ significantly between the corresponding outcross sources. The difference in number of pollen tetrads for stigmatic saturation between crossand self-pollination treatments was lowest, $\approx 7 \%$ to $10 \%$, for the primarily $V$. coryrmbosum cultivars ('Bluechip' and 'Meader'). The interspecific hybrid 'Northland' required $12 \%$ to $17 \%$ more self-pollen for stigmatic saturation.

Potential differences in pollen size between these tetraploid cultivars probably do not account for the saturating pollen deposition differences reported here, since 1) mean pollen size varies primarily along ploidy levels among blueberry species (Cockerham and 
Table 1. Mean number of pollen tetrads for stigmatic saturation in self- and cross-pollinated southern highbush blueberry.

\begin{tabular}{|c|c|c|}
\hline Pollination' & treatment & Applied \\
\hline $\begin{array}{l}\text { Fruiting } \\
\text { cultivar }\end{array}$ & $\begin{array}{l}\text { Pollen } \\
\text { source }\end{array}$ & $\begin{array}{l}\text { tetrads at } \\
\text { saturation (no.) }\end{array}$ \\
\hline Gulfcoast & $\begin{array}{l}\text { Gulfcoast } \\
\text { Georgia gem } \\
\text { O’Neal }\end{array}$ & $\begin{array}{l}294 \mathrm{a}^{2} \\
248 \mathrm{~b} \\
242 \mathrm{~b}\end{array}$ \\
\hline Georgia gem & $\begin{array}{l}\text { Georgia gem } \\
\text { Gulfcoast } \\
\text { O'Neal }\end{array}$ & $\begin{array}{l}295 a \\
260 b \\
251 b\end{array}$ \\
\hline O'Neal & $\begin{array}{l}\text { O'Neal } \\
\text { Gulfcoast } \\
\text { Georgia gem }\end{array}$ & $\begin{array}{l}241 a \\
207 b \\
201 b\end{array}$ \\
\hline
\end{tabular}

${ }^{2}$ Mean separation by Duncan's multiple range test, $P=0.05$.

Table 2. Mean number of pollen tetrads for stigmatic saturation in self- and cross-pollinated northern highbush and half-high blueberry.

\begin{tabular}{|c|c|c|}
\hline \multicolumn{2}{|c|}{ Pollination treatment } & \multirow{2}{*}{$\begin{array}{c}\text { Applied } \\
\text { tetrads at } \\
\text { saturation (no.) }\end{array}$} \\
\hline $\begin{array}{l}\text { Fruiting } \\
\text { cultivar }^{2}\end{array}$ & $\begin{array}{l}\text { Pollen } \\
\text { source }\end{array}$ & \\
\hline \multirow[t]{3}{*}{ Bluechip (HB) } & Bluechip & $213 a^{y}$ \\
\hline & Meader & $197 \mathrm{~b}$ \\
\hline & Northland & $195 \mathrm{~b}$ \\
\hline \multirow[t]{3}{*}{ Meader (HB) } & Meader & $256 \mathrm{a}$ \\
\hline & Northland & $235 \mathrm{~b}$ \\
\hline & Bluechip & $232 \mathrm{~b}$ \\
\hline \multirow[t]{3}{*}{ Northland $(\mathrm{HH})$} & Northland & $218 \mathrm{a}$ \\
\hline & Bluechip & $194 \mathrm{~b}$ \\
\hline & Meader & $186 \mathrm{~b}$ \\
\hline
\end{tabular}

${ }^{2} \mathrm{HB}=$ northern highbush, $\mathrm{HH}=$ half-high

${ }^{\mathrm{Y}}$ Mean separation by Duncan's multiple range test, $P=0.05$.

Galletta, 1976; Maas, 1977), and 2) the three combinations of pollen on each cultivar did not reveal consistent pollen-based trends across cultivars. The possibility that some stigmatic fluid was inadvertantly removed (by adherence to the thumbnail) during pollen application was not quantified, and thus cannot be ruled out as a potential artifact. Likewise, pollen application treatments were randomized but were not "double blind," which would have reduced any potential for inadvertant bias in the data. While these factors should be taken into account in future examinations. of this phenomenon, the significant and consistent results from this study suggest a number of interesting hypotheses and interpretations.

Recognition-based differential pollen hydration is one hypothesis worth examining. Pollen hydration reportedly can be blocked when the pollen-pistil genetic relationship is distant (Dumas and Gaude, 1981; Sarker et al., 1988). Perhaps hydration of self-pollen, via a glycoprotein receptor/recognition event between the stigmatic exudate and the pollen exine (Gudin and Arene, 1991), is only partial in blueberry, resulting in prolonged availability, rather than prolonged production, of exudate. Such a pollen-stigma recognition event would require reconsideration of Heslop-Harrison and Shivanna's (1977) limitation of Ericaceous plant self-incompatibility mechanisms to the style or ovary. Even if hydration of self-pollen is partial, pollen grain germination per se would not necessarily be prevented, but rather the number of germinating grains in a tetrad may be reduced. That self-pollination can result in seeded fruits (El-Agamy et al., 1982; Lang and Danka, 1991a; Lyrene, 1989) indicates that some self-pollen grains are clearly capable of germination.

Another hypothesis is that the stigma may remain receptive to pollen deposition by producing additional exudate when self-pollen is recognized (or, conversely, reducing exudation when cross-pollen is recognized). This type of "female choice" recognition event (Stephenson and Bertin, 1983) is feasible biochemically since, upon pollen hydration, the outer polysaccharide layer of the pollen aperture is disrupted, releasing enzymes that degrade the stigmatic papillae cuticles (Heslop-Harrison, 1979). Perhaps interactions between recognition proteins in the stigmatic fluid and the enzymatic complement in selfpollen prevent or reduce the rate of this lytic enzyme release, thus delaying stigmatic papillae degradation and prolonging the fluid/ papillae matrix.

This report is the first, in any flowering system known to us, in which a potential intraspecific pollen-stigma recognition event involving pollen hydration or pollen-mediated differential stigmatic fluid production has been observed. Such a recognition event before or at the step of pollen hydration has been previously thought to occur only for interspecific pollen-stigma interactions (Gaude and Dumas, 1987). Further documentation, such as by scanning electron microscopy (e.g., Wetzstein and Sparks, 1989) is warranted, as is determination of whether this phenomenon constitutes a subtle outcrossing strategy even in reportedly selfcompatible cultivars derived primarily of $V$. corymbosum. A continuum from partial to complete incompatibility (that may be altered by sporophyte/gametophyte age or environmental conditions) has been proposed as a likely reproductive system for many plants (Stephenson and Bertin, 1983). The relationship of the amount and genetic source of applied pollen tetrads to subsequent developed seed count and fruit size in southern highbush blueberry remains an important area for further study.

\section{Literature Cited}

Brewbaker, J.L. and SK. Majumder. 1961. Cultural studies of the pollen population effect and the self-incompatibility inhibition. Amer. J. Bot. 48:457-464

Cockerham, L.E. and G.J. Galletta. 1976. A survey of pollen characteristics in certain Vaccinium species. J. Amer. Soc. Hort. Sci. 101:671675.

Dumas, C.D. and T. Gaude. 1981. Stigma-pollen recognition and pollen hydration. Phytomorphology 31:191-201.

Dumas, C., C. Kerhhoas, G. Gay, and T. Gaude. 1986. Water content, membrane state and pollen physiology, p. 333-337. In: D.L. Mulcahy, G.B. Mulcahy, and E. Ottaviano (eds.). Biotechnology and ecology of pollen. SpringerVerlag, New York.

El-Agamy, S.Z.A., W.B. Sherman, and P.M. Lyrene. 1982. Pollen incompatibility in blueberries (Vaccinium spp.). J. Palynology 1\&103112.

Gaude, T. and C. Dumas. 1987. Molecular and cellular events of self-incompatibility. Intl. Rev. Cytol. 107:333-366.

Gudin, S. and L. Arene. 1991. Influence of the $\mathrm{pH}$ of the stigmatic exudate on male-female interaction in Rosa hybrida L. Sexual Plant Reproduction 4:110-112.

Heslop-Harrison, J. 1979. An interpretation of the hydrodynamics of pollen. Amer. J. Bot. 66:737743.

Heslop-Harrison, J. and K.R. Shivanna. 1977. The receptive surface of the angiosperm stigma. Ann. Bot. 41:1233-1258.

Jennings, D.L. and P.B. Topham. 1971. Some consequences of raspberry pollen dilution for its germination and/or fruit development. New Phytol. 70:371-380.

Lang, G.A. and R.G. Danka. 1991a. Honey beemediated cross- vs. self-pollination of 'Sharp. blue' blueberry affects fruit development period and fruit size.. J. Amer. Soc. Hort. Sci. 116:770773.

Lang, G.A. and R.G. Danka. 1991b. The influence of self- and cross-pollination on fruiting in southern highbush blueberries. HortScience 26:486. (Abstr.)

Lang, G.A. and R.G. Danka. 1992. Pollination aspects of fruit production in new southern highbush blueberries. Louisiana Agr. 35(2):34.

Lyrene, P.M. 1989. Pollen source influences fruiting of 'Sharpblue' blueberry. J. Amer. Soc. Hort. Sci. 114:995-999.

Lyrene, P.M. and W.B. Sherman. 1984. Breeding early-ripening blueberries for Florida. Proc. Fla. State Hort, Soc. 97:322-325.

Maas, J.L. 1977. Pollen ultrastructure of strawberry and other small-fruit crops. J. Amer. Soc. Hort. Sci. 102:560-571.

Sarker, R.H., C.J. Elleman, and H.G. Dickinson. 1988. Control of pollen hydration in Brassica requires continued protein synthesis, and glycosylation is necessary for intraspecific incompatibility. Proc. Nat!. Acad. Sci. USA 85:42404344.

Stephenson, A.G. and R.I. Bertin. 1983. Male competition, female choice, and sexual selection in plants, p. 109-149. In: L. Real (ed.). Pollination biology. Academic, New York.

Wetzstein, H.Y. and D. Sparks. 1989. Stigmapollen interactions in pecan. J. Amer. Soc. Hort. Sci. 114:355-359. 